\title{
Recruiting and Training for the Future - Marine Geospatial Information Learning
}

\author{
Shekhar MURTHY, India \\ IIC Technologies Academy \\ Duncan WARDLE, UK \\ IIC Technologies Group
}

\section{Derrick PEYTON, Canada \\ IIC Technologies Group}

Topic L: The hydrographic profession

\section{INTRODUCTION}

Amongst its wide range of geospatial services, IIC has been producing ENCs and Charts on behalf of hydrographic offices for more than a decade. During this time we have trained several hundred people in various elements of nautical cartography. We have recognised for some time that the competences of our people will be the biggest single differentiator for survival and growth in the future. The development of our people therefore plays a crucial role in aligning our business performance to organisational goals. We have seen over the past couple of decades a degree of academic rigour introduced into hydrography through the Standards of Competence of FIG/IHO/ICA. S5 (hydrographic surveying) and S8 (nautical cartography) that comprehensively outline the subject matter to be taught. However, the effectiveness of training is not just about getting the content right; it is as much about the method of delivery and the means of instruction is largely left to the discretion of the teaching establishment. When designing a course, the mode of learning needs to receive as much attention as the syllabus if the overall effectiveness of the training is to be maximised.

The IIC Academy has recently designed a Marine Geospatial Information (MGI) learning programme a Category B recognised course based on the S8 nautical cartography syllabus. We present it as a Case Study in the design of an effective mode of learning delivery. We start by looking at the needs of both organisation and individual, from which design principles can be derived for appropriate educational techniques. At the heart of the delivery is experiential learning, a "learn by doing" approach embedded within each element of the programme. This is supported by a blend of other teaching interventions and resources, including a "virtual faculty". The aim is to harness contemporary methods better to meet the demands of the modern generation of learners. Focusing more on the way we deliver course content is having a fundamental impact on the quality of the services we provide. This in turn is at the heart of all of our work in supporting the maritime infrastructure.

\section{IS THERE REALLY A PROBLEM IN THE CLASSROOM?}

Apparently there is a problem in the classroom. Research is showing that the new generation is not responding to traditional modes of instruction. We all face pressures to get value from the large investments made in educating our people. In 2010, through the IIC Academy, we set out to formalise our Marine Geospatial Information learning programme and bring it fully into line with the FIG/IHO/ICA S8 Standards of Competence. The S8 syllabus is very well defined and with some enhancements we were able to construct course content that would cover the full range of our project work in support of national hydrographic organisations. More problematic was the way we would deliver the programme. We wanted to look beyond conventional course structures based on continuous classroom based instruction. Our motivation was simple: improve the delivery of the 
programme, so improve individual performance and thus improve organisational performance. To start we asked a series of questions.

- What do we need from the course as an organisation?

- What do the students need (and want)?

- What are the strengths and the weaknesses of our existing training programmes?

- What can we learn from benchmarking other courses inside and outside our domain?

- How do we integrate the lessons learnt into the S8 MGI course design?

We will not dwell on the process that took us through answering these questions but present some of the findings that led to our design criteria for the MGI programme.

\section{ALIGNING ACADEMIC TRAINING TO ORGANISATIONAL STRATEGIES AND OBJECTIVES}

We have a Quality Management System in place whereby we strive to align our learning programmes to our organisational strategies and objectives. We review the effectiveness of training not just by tests and exams following training courses but later through performance metrics within our projects. As part of a continuous improvement programme we ask whether we can improve the effectiveness of our educational techniques and thus our performance and quality of output. The review we conducted as part of our MGI course design highlighted two inter-related elements that we felt could give our training more impact.

- Improved timing of the learning to optimise its impact.

- Ensuring the training is absolutely current and relevant to the work environment.

We read of debates as to whether training should be "just in time" or "just in case", often with it being presented as an "either - or" option. We analysed our own past training, looking at the knowledge we need, dividing it into three categories.

1. The tools of the trade: fast retreating are the days of pen and ink cartography. We are now in the digital world of MGI, and the new tools of the trade are software applications.

2. The underlying theory: it is essential to explain why something is done, i.e. what is going on in that black box - we need to prevent the unquestioning use of those software applications.

3. The practical application of both theory and tools of the trade; that is, understanding how something is done.

For the first category, the tools of the trade, we concluded it is neither just in time or just in case, it is a third category: "just has to be". Learning how to use a word processing package whilst you are writing a novel can only be demotivating and distracting. We find the same thing. Induction needs to ensure a degree of familiarity with the basic software tools of the trade. It yields rapid results. It motivates. It helps when teaching more of the "why and how". It needs to be out of the way before the more complex activities are undertaken.

For the second category, the underlying theory, we favour a "just in case" approach but with a caveat. Teaching the "how to do something" becomes more effective if some basic concepts are understood. Underlying this principle is the belief that to produce a quality chart or ENC, you need to know the full context of what you are doing - whether it be how a chart is used for navigation or how a border is constructed by the black box of modern software. The caveat comes in that the theoretical elements need to be refreshed and reinforced by seeing that theory in practice. Repetition and reinforcement of some of that theory is an additional overhead but necessary at the point the "just in time training" may be delivered. 
Finally, for the third category of practical applications, then "just in time" wins hands down. Teach, and then consolidate as quickly as possible, is a well-trodden and proven path with which we have no reason to argue.

A statement of the blindingly obvious: to provide services effectively our knowledge has to be absolutely up-to-date. "Knowledge currency" is the basis of every aspect of our work. We need to know the latest standards and the latest techniques. This is a fundamental connection between the MGI learning programme and the organisational objectives. Without this we cannot gain a competitive advantage or undertake our work efficiently. We have to ensure that the teaching of the subject matter is continuously kept relevant. So we find course delivery needs to weave into the framework a blend, mixing "just have to" with "just in case" with "just in time". This means accepting repetition. There are some competences and knowledge that have to be laid as a foundation but then repeated and reinforced through consolidation at a later time through practical experiences.

\section{GIVING MORE REALISM AND RELEVANCE FOR THE NEW GENERATION OF MILLENNIALS}

Next, we turned our attention to the "target audience" - the new recruits and potential students and what they might need (and want). This new generation is different and will change our world of hydrography (Casey, 2009). They go by various names, such as the download generation or digital natives (in contrast to the digital immigrants who have not had the benefit of growing up immersed in the new technology) (Prensky 2001). We use the term "millennials". What are their characteristics? They are said to be a confident lot - they have been raised by parents who believed in their selfesteem. They question authority and are not afraid of debate. Some may see these as a challenge in the classroom but in the workplace they are strengths to be harnessed. It still seems that much teaching is: "rooted on how to tame youngsters to our way of living and working rather than to redesign our academic and workspaces to take advantage of their strengths" (Murthy 2011).

When it comes to learning, millennials exhibit several characteristics of which to take account.

- The Classroom. Research indicates that $65 \%$ of teaching is still conventional classroom based. Whilst we believe that the role of a teacher as a facilitator cannot be over-emphasized, the "sage on the stage" approach remains dominant decades after it was identified as needing reform.

- The Content. The immediacy of everything surrounding the millennial brings a desire for realism and relevance to the education rather than abstraction. An approach to learning through case-studies with a degree of real world realism has been in vogue for several years and is well suited to this generation.

- Assignments. We are told millennials are turned off with boring, structured, and bookish assignment submissions. They exhibit a "challenge me" attitude. The assignments have to be tailored accordingly - not an easy thing to achieve. This may all be considered in line with current fads but should it be us the teachers that adapt and keep in tune with current fads, as it is this that draws their interest?

If it is the millennials that are going to form our future workforce, then we take the view our educational policies, methods, and processes must be millennial-centric, rather than historic.

"our digital immigrant instructors, who speak an outdated language (that of the pre-digital age), are struggling to teach a population that speaks an entirely new language" (Prensky 2001).

We were relieved to find more coincidence than clashes between the organisational needs and those of the individual. There was enough to convince us that we had to change the emphasis of tuition. It is also too simplistic to make the leap from the profile of millennial learners and assume that elearning is the answer. Evidence points to the importance of interaction and collaborative activities. Also, it is too easy to dismiss altogether classroom teaching as being outmoded. We took the view 
that classroom teaching has a major part to play but as expressed by Shepherd (2011) that classroom courses "are at their best when collaborative and practical" and at their worst "when trainer centred as sage on the stage". Realism and relevance are two by-words we took to the design phase.

\section{THE IIC ACADEMY MGI LEARNING PROGRAMME DEFINED}

It is always difficult to avoid passing fads but the IIC Academy has studied the effectiveness of methods of teaching within academic circles (Murthy 2008, 2011) from which we were able to derive some core design principles that would meet our objectives for the MGI programme.

- Learn by doing (experiential learning techniques).

- Mix our teaching methods between traditional and unconventional (blended learning).

- Providing greater access to learning resources and the "virtual faculty".

\section{Experiential Learning at a Macro and Micro Level}

The first of our design principles - experiential learning - is not new. As an academic doctrine it has its origins back in the seventies. Experiential learning is what it says: learning through experience. The key is however a cycle that moves from the experience, through to reflecting on that experience, then consolidation of the theoretical ideas behind that experience and moving into applying what has been learnt at the start of another cycle of learning (Murthy and Naraharisetty 2008). Experiential learning lends itself to hydrography. Our subject matter is highly practical. It attracts practical people. It fits the needs of millennial learners. How do we embed it more fully into our programmes? We have sought to do this at two levels - what might be termed the micro and the macro levels.

- At the micro level, that is, at every possible building block of the course, we look to base our learning around some form of experience. These move through the cycle of: do - reflection teach theory - apply learning. Some doubters said, well surely this is what we already do in the classroom - you have just given it a fancy name? It is true most hydrographic and cartographic training has grown up around interspersing theory with practical exercises. The subtle but important difference is a move towards a more conscious adoption of that full cycle, whereby the theory is preceded by learning exercises and followed by group reflection before moving to consolidation. Combined with this, we base the exercises on real-life case studies and follow the real-world "stories" ideas of Schank (2007).

- At the macro level we have designed the course from the beginning (not as an afterthought) to be modular and to be taken over an extended period. There is a practical consideration here also, as it better fits with our organisational needs to balance training and project work. Again, we do not claim originality, merely that the choice of this design approach is to do with the effectiveness of the learning and not convenience. For this approach to work, the modules and the intervening periods have to be considered part of a full cycle of experiential learning. So where practicable, each module will be followed with project work, which will be supported by learning interventions to provide both the reflection and consolidation parts of the cycle.

\section{Blended Learning - Beyond E-Learning}

The second design principle is the implementation of a more "mixed economy" of methods. Few educators may admit to still being sage on the stage based in their training, but research findings say it is still dominant. It takes effort and resources to move towards the realism and variety that is demanded by the current generation of learners. Our experiential learning approach takes us further in that direction but we needed more imagination to give that much needed variety. So within the mix, we are developing e-learning components but importantly these are a supplement, not a substitute in the learning mix. We want to allow flexibility and to allow students access to additional teaching material away from the classroom, to allow them to self-pace their learning. But we also 
want our e-learning to look beyond the individual. We do not want to see students retreat into isolation. On the contrary, as a company we need to develop more collaborative working, not less. So our e-learning is being developed around shared experiences and workspaces wherever we can.

\section{Learning Resources and the Virtual Faculty}

Millennials have grown up with almost instantaneous access to infinite resources offered by the internet (to illustrate type "sage on the stage" into a search engine and you get 64 million plus results in .2 seconds). Do we make our students forego this and revert to the traditional research in a library? From a business perspective we are just as concerned as any higher educational establishment with diligent research that pays attention to the provenance of information. But we are also concerned with speed. A recent research study claimed that the average knowledge worked spends seven hours a week searching for information from within their company (Shepherd 2011). Shepherd states that not only is this a waste of time (and money) but that it was frustrating for the individuals (and those they interrupted). We concluded the need was to build more of an infrastructure of learning resources that blended the traditional and the modern.

There was a more important element of resource: access to experts. In addition to its tutors, the IIC Academy has access to deep domain expertise in the subjects we teach amongst the IIC practitioners spread across the globe. How do you harness this powerful resource to benefit the learning programme? We introduced the notion of Subject Matter Experts (SMEs). SMEs now play several key roles and are our "virtual faculty". All are passionate about their field and we had no difficulty in persuading people to be involved in our training programmes. For example, in terms of the teaching methods they provide an additional resource to keep us current, they provide new case studies based on recent projects and they provide a source of advice to students and tutors alike. Through the virtual faculty we supplement the abstraction of the web with professional role models.

\section{THE SUCCESS OF THE MGI PROGRAMME IN DELIVERING A CATEGORY B PROGRAMME}

The hydrographic community is fortunate to have well-thought through learning content (in S5 and S8). However good this content may be, it needs to be complemented by an effective mode of delivery. There are many trends and fads; it is fair to say educational theory has its fair share of buzzwords. Selection of the right methodology will benefit from a structured process that looks both at the organisational needs and those of the students. This needs to be followed by choosing appropriate teaching techniques. We do not suggest there is a silver bullet or any revolutionary concepts, more that carefully applied innovation can make significant improvements.

There has to be an acceptance that methods must change; one size has never fitted all and certainly does not with today's millennial learners. A beneficial move is the shift to a more blended delivery mechanism, mixing the way we engage with students and the way they engage with us. The nature of our field lends itself more than most subjects to the more formal adoption of experiential learning. This emphasises the practical side of learning but within a well-established educational framework. A delivery that is extended, flexible and modular, if designed correctly, should provide more effective way of delivering long term learning and repay the investment of time and effort in course construction. Outside traditional academia the concept of a "virtual faculty" of Subject Matter Experts provides a means of retaining strong human learning interventions.

Whether private or public sector, we should share the common goal of gaining better value from our training investment as it is this that in turn improves our performance through the quality and the calibre of our people. By adopting an approach that pays equal attention to delivery and content, we believe we can have learning programmes that meets both the exacting standards of S8, whilst at the same time delivering that content more effectively. 


\section{REFERENCES}

Casey. M. 2009. "How The Download Generation Will Drive Electronic Charting In A New Direction". Paper presented at $3^{\text {rd }}$ International ECDIS Conference, Singapore, 19-21 Oct.

Murthy, S. \& Naraharisetty, P. 2008. "Enhancing Experiential Learning Through E-Pedagogy". Paper presented at TARC International Conference, Malaysia.

Murthy, S. 2011. Millennial-Centric Learning: Revisiting Education with Changed Mindset. Paper presented at NamCon11, ASBM, Bhubaneswar, India.

Prensky, M. 2001. "Digital Natives, Digital Immigrants". From On the Horizon MCB University Press, Vol. 9 No. 5, October 2001. Accessed June 2012 http://www.marcprensky.com/writing/prensky\%2020digital\%20natives,\%20digital\%20immigrants\%20-\%20part1.pdf

Schank, R. 2007. "The Story Centred Curriculum". eLearn Magazine Accessed June 2012 http://elearnmag.acm.org/featured.cfm?aid=1266881

Shepherd, Clive. 2011. The Architect of Learning. Marston Gate: Onlignment

\section{BIOGRAPHIES}

Shekhar MURTHY

Shekhar Murthy is the President of IIC Academy at Visakhapatnam, India. In a career of nearly 30 years, he has held positions in learning and development in the Navy, engineering colleges and industry writing several papers on holistic lifelong learning, e-learning, just-in-time techniques adapted to learning, pedagogy and experiential learning. He is currently pursuing his doctoral studies in the area of "Building 21st Century Learning"

\section{Duncan WARDLE}

Course Director for the IIC Academy Marine Geospatial Information Cat B course, Duncan Wardle has a degree in Geography and an MBA. He has been involved for thirty five years in nautical cartography and the surrounding science. During a career largely in the public sector, but for the last five years with the IIC Technologies Group he has been involved in the training and development of hydrographic professionals.

\section{Derrick PEYTON}

Chief Executive and Chairman of the IIC Academy Governing Council, Derrick Peyton has been involved for over three decades in the world of hydrography. With an engineering degree, a Masters and MBA he is a qualified hydrographic surveyor to Cat A standard. He has actively been engaged in education throughout his career with teaching experience. 
CONTACT DETAILS (of corresponding author only)

Derrick PEYTON

IIC Technologies Group

Address

City

COUNTRY

Tel.: +

Fax: +

Email: derrick.peyton@iictechnologies.com

Web site: www.iictechnologies.com

LinkedIn account:

Facebook account:

Twitter account: 